\title{
Photoreactivation in an archaeon from geothermal environments
}

\author{
Dennis W. Grogan \\ Author for correspondence: Dennis W. Grogan. Tel: +1 513556 9748. Fax: +1 5135565299. \\ e-mail: Dennis.Grogan@UC.edu
}

Department of Biological Sciences, University of Cincinnati, PO Box 210006 Cincinnati, OH 45221-0006, USA

\author{
UV-inactivated cells of Sulfolobus acidocaldarius rapidly regained viability \\ when exposed to white light. This recovery was strictly dependent upon \\ illumination with visible light and was not attenuated by prior dark- \\ incubation. The kinetics of photoreactivation were determined at several \\ temperatures and at several wavelengths of light. The results obtained in vivo \\ were consistent with a DNA photolyase having a broad action spectrum. \\ Photoreactivation of S. acidocaldarius apparently represents the first DNA \\ repair process to be measured in an archaeon which grows optimally near \\ $80^{\circ} \mathrm{C}$.
}

Keywords: Sulfolobus acidocaldarius, UV inactivation, DNA repair, action spectrum

\section{INTRODUCTION}

Changes to the structure of DNA pose a serious threat to the survival and propagation of prokaryotes, as these are haploid organisms with little genetic redundancy. Detailed biochemical and genetic studies on Escherichia coli and other bacteria have revealed several different molecular systems used by bacterial cells to cope with DNA damage. The diverse array of mechanisms so far identified reflects not only the central importance of repairing DNA, but also the variety of structural changes that can occur in DNA and that must be eliminated (Sancar \& Sancar, 1988).

The apparent importance of a broad repertoire of DNArepair enzymes for mesophilic bacteria raises obvious questions for other prokaryotes which thrive in physically and chemically stressful environments. Many archaea (Woese et al., 1990) have been isolated in recent years from geothermal environments, for example. These extreme thermophiles, or 'hyperthermophiles', provide a dramatic example of such prokaryotes, growing optimally at temperatures ranging from $80^{\circ} \mathrm{C}$ to $105^{\circ} \mathrm{C}$ (Stetter et al., 1990). Such growth temperatures can accelerate spontaneous chemical modifications of DNA by orders of magnitude (Lindahl, 1993) and may thus make efficient repair of damaged DNA critical to the function and survival of these archaeal cells. Unfortunately, most archaea isolated from geothermal habitats do not lend themselves to manipulation by standard microbiological techniques, and, to the author's knowledge, no functional evidence of DNA repair in any of these archaea has been reported in the literature.
Sulfolobus acidocaldarius is an aerobic archaeon that grows optimally at about $80^{\circ} \mathrm{C}$ and $\mathrm{pH} 3$ (Grogan, 1989). It has the advantage for experimental studies that it grows heterotrophically on a variety of simple media, forms colonies from single cells, and has yielded a number of useful mutant strains (Grogan \& Gunsalus, 1993). The present study reports physiological evidence of an enzymic mechanism in S. acidocaldarius which uses light energy to repair UV-induced damage to chromosomal DNA.

\section{METHODS}

Strains and growth conditions. S. acidocaldarius strains DG6 (ATCC 49426) and DG185 (ATCC 33909) were clonally purified by streaking cells on solid medium. These two wildtype strains exhibit the same profile of restriction fragments (Grogan, 1989; McAfee et al., 1995) but have different histories (Grogan, 1991) and yield colonies of slightly different opacity on some solid media (unpublished results).

Cultures were grown from single colonies in xylose/tryptone medium (Grogan \& Gunsalus, 1993) at $80^{\circ} \mathrm{C}$ with continuous aeration. Numbers of viable cells were determined by serial $1: 10$ dilution of cell suspensions in Sdil buffer (Grogan, 1996), followed by spreading suitable dilutions on plates of solidified xylose/tryptone medium. [Sdil buffer contained ( $\mathrm{g}$ per litre distilled water): $\mathrm{K}_{2} \mathrm{SO}_{4}, 1 \cdot 0 ; \mathrm{MgSO}_{4} .7 \mathrm{H}_{2} \mathrm{O}, 0 \cdot 2$; L-glutamic acid, $0 \cdot 2$; gelatin, $0 \cdot 1$. The $\mathrm{pH}$ was adjusted to $3 \cdot 5$ with $\mathrm{H}_{2} \mathrm{SO}_{4}$ and the solution was sterilized by autoclaving.] Colonies (1-2 mm diameter) formed on the solid medium within $6 \mathrm{~d}$ incubation at $75^{\circ} \mathrm{C}$. Under these conditions, unirradiated cell suspensions yielded colonies at efficiencies of $\geqslant 64 \%$ of cells plated, as judged by the following empirically determined relationship: no. of cells $\mathrm{ml}^{-1}=\left(8 \times 10^{8}\right)\left(D_{600}\right)$, where the concentration of cells in a reference culture was determined by 
direct microscopic count and $D_{600}$ is the attenuance at $600 \mathrm{~nm}$ due to light scattering, determined in $16 \mathrm{~mm}$ diameter culture tubes in a Milton-Roy model 21 spectrophotometer.

UV irradiation. Cells were harvested at $22^{\circ} \mathrm{C}$ by centrifugation from growing cultures whose cell densities were between 1 and $3 \times 10^{8}$ cells $\mathrm{ml}^{-1}$; under the growth conditions used in this study, stationary-phase cultures have a cell density of about $9 \times 10^{8}$ cells $\mathrm{ml}^{-1}$. Cells were resuspended in Sdil and centrifuged. The supernatant was thoroughly drained from the pellet and the washing procedure was repeated. The washed cells were finally resuspended in sufficient $S$ dil to yield approximately $1.6 \times 10^{8}$ cells $\mathrm{ml}^{-1}$.

The following manipulations were done under dim red light. Cell suspensions were transferred to an open glass Petri dish, yielding an average depth of $1 \mathrm{~mm}$. The dish was placed directly under a $15 \mathrm{~W}$ germicidal lamp and continuously agitated during the total exposure $(40 \mathrm{~s})$. This corresponded to a total incident dose of $200 \mathrm{~J} \mathrm{~m}^{-2}$, of which $70 \%$ of the energy (i.e. $140 \mathrm{~J} \mathrm{~m}^{-2}$ ), came from wavelengths shorter than about $295 \mathrm{~nm}$ (see Calibrations, below). The UV transmission of $1 \mathrm{~cm}$ Sdil at $254 \mathrm{~nm}$ was measured in a dual-beam spectrophotometer and found to be $96 \%$ relative to distilled water. Cell suspensions not being diluted or plated under dim red light were stored in darkness. Under these conditions, the observed UV-survival curves of $S$. acidocaldarius strains are slightly sigmoidal (E. R. Wood \& D. W. Grogan, unpublished results). A lag (i.e. shoulder) lasts $2-20 \mathrm{~s}$, depending on the cell preparation; this is followed by exponential inactivation with a first-order rate constant (base e) of about $-0.5 \mathrm{~s}^{-1}$. By about $60 \mathrm{~s}$, the rate of inactivation slows; therefore, $40 \mathrm{~s}$ treatment represents about the maximal dose that falls within the exponential phase of inactivation, and was used for most experiments.

Photoreactivation with white light. Cell suspensions in horizontally placed glass vials or in micro-dilution plates with clear plastic covers (polystyrene or acrylic resin) were illuminated from above by a bank of six evenly spaced, cool-white fluorescent lamps (Sylvania 15T12-D) at a distance of $30 \mathrm{~cm}$. The total incident flux into the suspension was about $13 \mathrm{~W} \mathrm{~m}^{-2}$ under these conditions and the total depth of the suspension was less than $6 \mathrm{~mm}$. At regular intervals during illumination, the suspensions were mixed and samples were withdrawn and processed under dim red light to enumerate viable cells. Tests of possible dark repair were conducted in the same way, except that the suspensions were stored in the dark and were sampled over longer periods of time.

To test the effects of temperature on photoreactivation, suspensions of the two strains were illuminated in parallel in micro-dilution plates maintained at four different temperatures under the bank of fluorescent lamps. The temperatures maintained in the sample wells were measured with a miniature thermocouple probe in $200 \mu \mathrm{l}$ of water under the test conditions.

Action spectrum. DG185 cells were washed and UV-irradiated as described, except that UV exposure was $30 \mathrm{~s}$. The resulting cell suspension was stored in darkness at room temperature for at least $4 \mathrm{~h}$. Aliquots $(500 \mu \mathrm{l})$ were then transferred to a $1 \mathrm{~cm}$ cuvette and warmed to $50^{\circ} \mathrm{C}$ in the dark $(30 \mathrm{~min})$. The cuvette was transferred to the sample chamber of a spectrofluorometer (Aminco-Bowman J4-8203) whose sample block was heated (by circulating water) to maintain a temperature of $50{ }^{\circ} \mathrm{C}$ within the cuvette. The sample was irradiated by light of $11 \mathrm{~nm}$ bandwidth from the high-pressure xenon arc lamp via the excitation monochromator of the spectrofluorometer (maximal incident intensity of about $4 \mathrm{~W} \mathrm{~m}^{-2}$ ). The suspension was stirred at 2-3 min intervals and assayed every $5 \mathrm{~min}$ for viability (as described above) by withdrawing $22 \mu \mathrm{l}$ aliquots. Suitable dilutions of each sample in Sdil buffer were plated in duplicate.

The number of c.f.u. per aliquot was used to calculate a firstorder rate constant by least-squares fitting of the relationship $\ln \left(N / N_{0}\right)=k t$,

where $N_{0}$ is the viability immediately before monochromatic illumination, $N$ is the viability at time $t \mathrm{~min}$, and $k$ is the resulting first-order rate constant of photoreactivation at that wavelength. Three independent spectra, using cell suspensions from different cultures on different days, were determined in this manner. The values were averaged and corrected for photon flux as described below.

Calibrations. All light intensities were measured by a radiometer (Yellow Springs Instrument, model 65) at room temperature. Since the age of the UV lamp used in this study was unknown, its spectral quality was estimated by the fraction of intensity absorbed by a Pyrex glass lid, whose transmission spectrum (Cary 1E spectrophotometer, $2 \mathrm{~nm}$ bandwidth) showed a transmission cutoff at about $295 \mathrm{~nm}$. This lid blocked $70 \%$ of the UV lamp output, as determined by ferric oxalate actinometry and radiometer measurements.

The photoreactivation rate constants were corrected as follows to yield an action spectrum. The relative incident light intensity on the face of the cuvette (i.e. the monochromator output) was determined for each monochromator setting by multiple measurements with a radiometer probe mounted in the sample chamber. The relative light intensity on the Sulfolobus cells in suspension was calculated by correcting the above data for the slight absorbance of the polystyrene cuvette below $400 \mathrm{~nm}$. The relative photon flux at each monochromator setting was determined by multiplying each relative intensity above by the corresponding wavelength. Finally, the photoreactivation rates measured at each wavelength were averaged and divided by the relative photon flux; this yielded the relative biological response per incident photon of the corresponding wavelength. Within the experimental error estimated by duplicate measurements at one lamp output, rates of photoreactivation were proportional to the incident light intensity over the wavelength range studied. This suggests that an approximate time/intensity reciprocity was achieved under the experimental conditions.

\section{RESULTS}

\section{Kinetics of photoreactivation}

Suspensions of $S$. acidocaldarius cells irradiated for $40 \mathrm{~s}$ with a germicidal lamp typically retained $0.3-0.02 \%$ of their original viability. When these suspensions were transferred to glass vials and illuminated with white light, viability increased rapidly as a function of time. The results of three independent trials at about $24^{\circ} \mathrm{C}$ for each of two wild-type strains are shown in Fig. 1. Whereas the efficiency of photoreactivation varied among the trials, the overall kinetics were similar. During the first $30 \mathrm{~min}$, c.f.u. increased approximately exponentially, but by $100 \mathrm{~min}$ were increasing slowly, if at all. Logarithmic plots of the data thus yielded curves resembling hyperbolic functions (Fig. 1). Original viable 


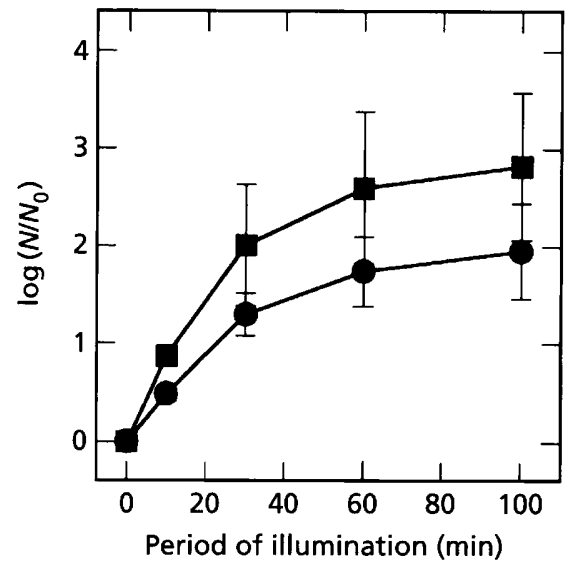

Fig. 1. Photoreactivation kinetics of $S$. acidocaldarius. Symbols show the mean value of three independent determinations; error bars show the standard deviations. O. Strain DG6; strain DG185.

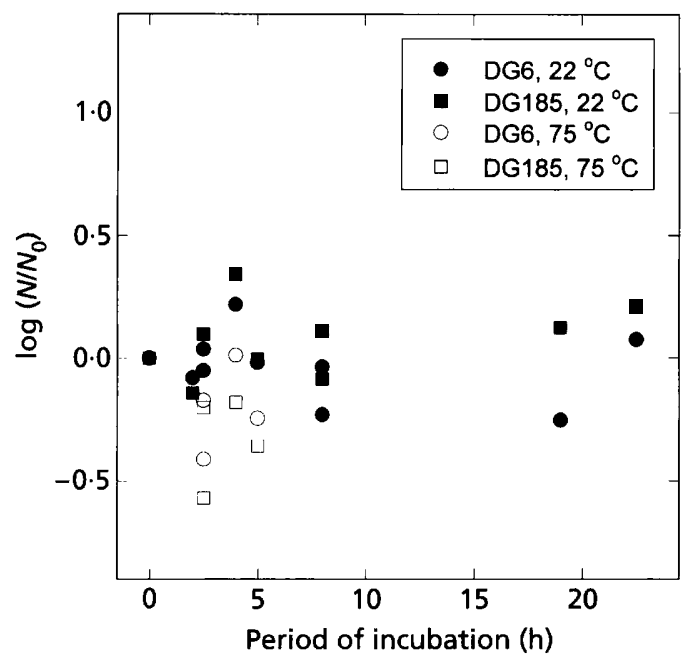

Fig. 2. Viability of UV-treated suspensions stored in darkness. Each symbol represents one experimental measurement; note that the vertical axis is expanded and the horizontal axis compressed relative to Fig. 1 .

titres of the suspensions were $0 \cdot 9-1 \cdot 8 \times 10^{8}$ c.f.u. $\mathrm{ml}^{-\mathbf{1}}$; viability after UV treatment and 100 min illumination in the experiments of Fig. 1 ranged from 7 to $27 \%$ of the corresponding initial value.

The possibility was tested that the observed increase in viability did not require visible light. A portion of the same UV-treated cell suspension used in a photoreactivation assay was incubated in darkness but otherwise assayed for viability in the same way as illuminated suspensions. No significant changes in viability occurred under these conditions in several independent trials using both wild-type strains (Fig. 2, solid symbols). This

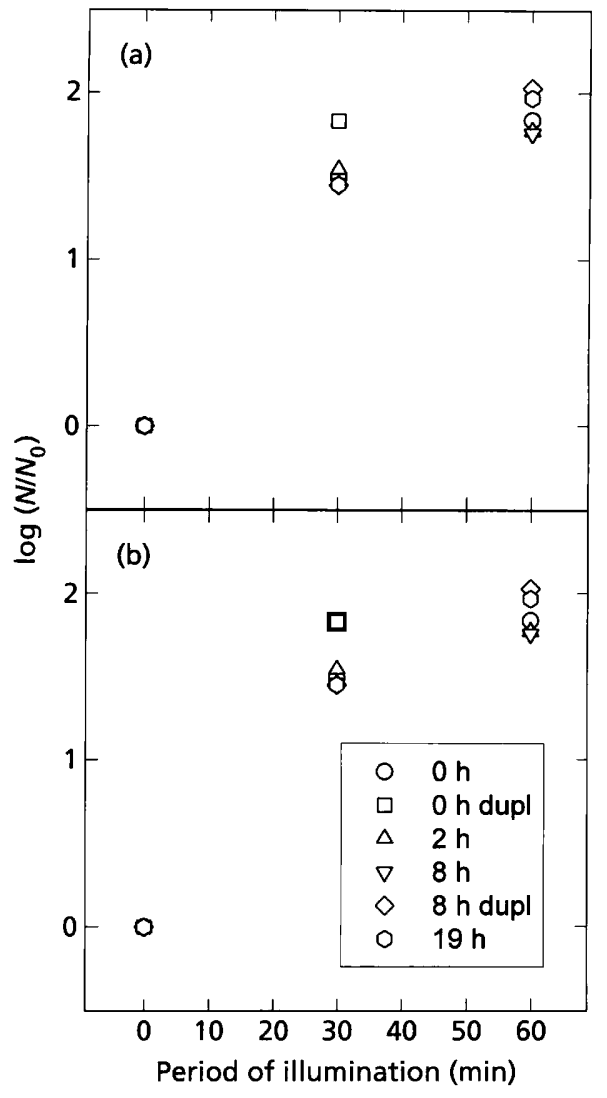

Fig. 3. Photoreactivation of cell suspensions stored in darkness: (a) strain DG6; (b) strain DG185. Each symbol represents one experimental measurement. Inset, hours of prior dark storage for each symbol type; 'dupl', duplicate cell suspension.

confirmed that the results of Fig. 1 depict a lightdependent process. Viability of UV-irradiated cells also did not increase when incubated at $75^{\circ} \mathrm{C}$ in the dark (Fig. 2, open symbols). Thus, no physiological evidence of 'dark repair' processes could be demonstrated under the conditions of this study.

S. acidocaldarius cells were tested for their ability to be photoreactivated after prolonged incubation at $22^{\circ} \mathrm{C}$ in the dark. Strains DG6 and DG185 were irradiated for $40 \mathrm{~s}$ with UV, as described in Methods. Aliquots of the suspensions were withdrawn after varying times of incubation in the dark, and the kinetics of photoreactivation were determined. The results (Fig. 3) show that $S$. acidocaldarius cells retain their ability to be photoreactivated during prolonged storage in dilution buffer at $22^{\circ} \mathrm{C}$.

\section{Effect of photoreactivation temperature}

In order to estimate the temperature-dependence of photoreactivation, cell suspensions were assayed for photoreactivation at four different temperatures in parallel : $7 \pm 1,24 \pm 2,40 \pm 1$, and $50 \pm 1{ }^{\circ} \mathrm{C}$. (The effects 


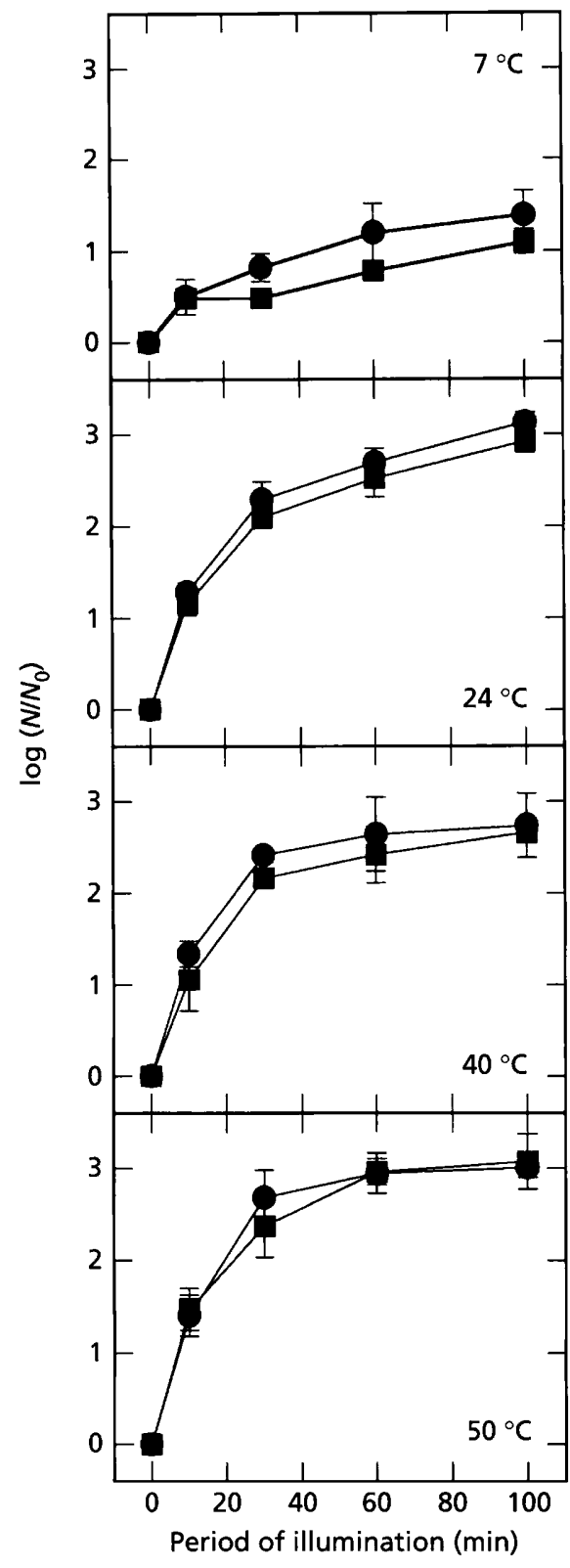

Fig. 4. Photoreactivation at four different temperatures. Symbols show the mean values of four to six determinations at the temperature indicated; error bars show \pm one standard deviation. Strain DG6; $\mathbf{a}$, strain DG185.

of lower and higher temperatures were difficult to study in the apparatus due to high evaporation rates and temperature instability.) The results of several independent trials are shown in Fig. 4. The kinetics of photoreactivation were similar at 50,40 , and $24^{\circ} \mathrm{C}$, but much slower at $7^{\circ} \mathrm{C}$. The values of $\log \left(N / N_{0}\right)$ at $10 \mathrm{~min}$ were used to estimate the initial, exponential rate of photoreactivation under these conditions. Comparisons among these values (Table 1 ) indicate that temperature over the range of $50-24^{\circ} \mathrm{C}$ had relatively little effect on the initial rate of photoreactivation but had significant effect at $7{ }^{\circ} \mathrm{C}($ Table 1$)$.
Table 1. Estimates of initial rates of photoreactivation of $S$. acidocaldarius at different temperatures

Viabilities of the suspensions before photoreactivation ranged from $0.02 \%$ to $0.05 \%$ of the original viability.

\begin{tabular}{|clcc|}
\hline $\begin{array}{c}\text { Temp. } \\
\left({ }^{\circ} \mathrm{C}\right)\end{array}$ & Strain & $\begin{array}{c}\text { Initial rate } \\
\left(\mathbf{m i n}^{-\mathbf{1}} \pm \mathbf{S D}\right)\end{array}$ & $\begin{array}{c}\text { No. of } \\
\text { trials }\end{array}$ \\
\hline 7 & DG6 & $0 \cdot 050 \pm 0 \cdot 020$ & 6 \\
7 & DG185 & $0 \cdot 048 \pm 0 \cdot 007$ & 6 \\
24 & DG6 & $0 \cdot 129 \pm 0 \cdot 098$ & 4 \\
24 & DG185 & $0 \cdot 116 \pm 0 \cdot 098$ & 4 \\
40 & DG6 & $0 \cdot 136 \pm 0 \cdot 013$ & 5 \\
40 & DG185 & $0 \cdot 122 \pm 0 \cdot 013$ & 5 \\
50 & DG6 & $0 \cdot 140 \pm 0 \cdot 022$ & 6 \\
50 & DG185 & $0 \cdot 147 \pm 0 \cdot 022$ & 6 \\
\hline
\end{tabular}

Table 2. Observed rate of photoreactivation at different wavelengths

Units for rate constants and standard errors of least-squares fitting of viability data are $0.001 \mathrm{~min}^{-1}$; ND, not determined.

\begin{tabular}{|c|c|c|c|c|c|c|}
\hline \multirow{2}{*}{$\begin{array}{l}\text { Expt... } \\
\text { Wavelength } \\
(\mathrm{nm})\end{array}$} & \multicolumn{2}{|c|}{1} & \multicolumn{2}{|c|}{2} & \multicolumn{2}{|c|}{3} \\
\hline & Rate & SE & Rate & $\mathrm{SE}$ & Rate & SE \\
\hline 360 & \multicolumn{2}{|c|}{ ND } & $42 \cdot 8$ & $3 \cdot 7$ & $25 \cdot 0$ & $4 \cdot 0$ \\
\hline 380 & $44 \cdot 7$ & $3 \cdot 1$ & $60 \cdot 6$ & 3.8 & $41 \cdot 1$ & $5 \cdot 1$ \\
\hline 400 & $42 \cdot 2$ & $2 \cdot 6$ & $38 \cdot 2$ & $4 \cdot 4$ & \multicolumn{2}{|c|}{ ND } \\
\hline 410 & $45 \cdot 8$ & $3 \cdot 6$ & $59 \cdot 3$ & $4 \cdot 4$ & 33.8 & $4 \cdot 4$ \\
\hline 420 & $42 \cdot 7$ & $2 \cdot 2$ & $60 \cdot 8$ & $3 \cdot 8$ & 35.9 & 1.8 \\
\hline 430 & $53 \cdot 0$ & $7 \cdot 6$ & 78.7 & $5 \cdot 5$ & $50 \cdot 7$ & $7 \cdot 3$ \\
\hline 440 & $52 \cdot 4$ & $4 \cdot 6$ & $77 \cdot 5$ & $5 \cdot 1$ & $48 \cdot 6$ & $8 \cdot 3$ \\
\hline 450 & $82 \cdot 9$ & $5 \cdot 0$ & $62 \cdot 8$ & $2 \cdot 8$ & $62 \cdot 4$ & $5 \cdot 4$ \\
\hline 460 & $65 \cdot 0$ & $6 \cdot 2$ & $70 \cdot 0$ & 8.0 & $53 \cdot 3$ & 3.8 \\
\hline 470 & $105 \cdot 7$ & $29 \cdot 1$ & $79 \cdot 2$ & $4 \cdot 7$ & $53 \cdot 4$ & $3 \cdot 0$ \\
\hline 480 & $85 \cdot 4$ & $15 \cdot 2$ & $41 \cdot 4$ & 3.9 & $23 \cdot 1$ & $7 \cdot 4$ \\
\hline 500 & $7 \cdot 5$ & $5 \cdot 1$ & $14 \cdot 0$ & 3.6 & \multicolumn{2}{|c|}{ ND } \\
\hline 525 & -11 & 4.7 & \multicolumn{2}{|c|}{ ND } & \multicolumn{2}{|c|}{ ND } \\
\hline
\end{tabular}

\section{Action spectrum of photoreactivation}

Using a high-intensity lamp and monochromator, the efficiency of photoreactivation in vivo was measured as a function of the wavelength of light. Strain DG185 was assayed at $50^{\circ} \mathrm{C}$; these conditions were the most favourable for photoreactivation among those tested in the present study, and allowed frequent sampling without excessive evaporation. As expected from the limited light intensities obtainable with monochromatic light, the viability increased significantly more slowly than under white-light illumination and remained exponential over the entire $25 \mathrm{~min}$ assay period, as judged by the standard errors of fitting duplicate viability determinations to an exponential function. As shown in Table 2, these errors generally fell within the variation in 


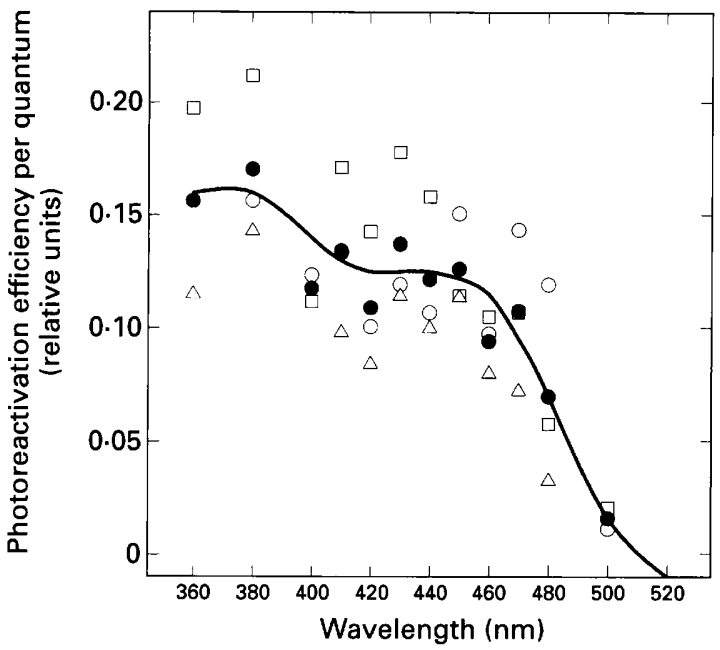

Fig. 5. Action spectrum of photoreactivation. The data of Table 2 were corrected for photon flux at each wavelength (three trials, open symbols) and averaged (solid circles).

rates observed among independent trials (Table 2, Fig. $5)$. The observed photoreactivation rates were averaged and normalized (see Methods) to yield the relative action spectrum shown in Fig. 5 .

\section{DISCUSSION}

The results presented above show that in the archaeon $S$. acidocaldarius visible light efficiently reverses the lethal effect of prior UV radiation. This phenomenon, known as photoreactivation, has been observed in a wide variety of unicellular organisms, including eukaryotes, bacteria and archaea (Harm, 1980; Jagger et al., 1970; Fitt et al., 1983). Photoreactivation of $S$. acidocaldarius was efficient under the conditions employed. In the experiments of Fig. 4, for example, viability increased from values of $0.02-0.05 \%$ at $0 \mathrm{~min}$ to values of $25-58 \%$ at $100 \mathrm{~min}$. Halophilic and methanogenic archaea have demonstrated photoreactivation (Fitt et al., 1983; Kiener et al., 1985), and the DNA photolyase of the methanogen Methanobacterium thermoautotrophicum has been purified and characterized in detail (Kiener et al., 1989). However, photoreactivation was not previously known for a member of the crenarchaeote subdivision (Woese et al., 1992), which includes many sulfur-metabolizing archaea from geothermal environments. In view of its optimal growth temperature of about $80^{\circ} \mathrm{C}$ (Grogan, 1989), S. acidocaldarius is probably the most thermophilic organism in which photoreactivation has to date been observed.

The response of UV-inactivated $S$. acidocaldarius cells to visible light resembled the responses of archaea, bacteria, and eukaryotes whose photoreactivation mechanisms have been shown to be mediated by corresponding DNA photolyases (Kiener et al., 1989; Sancar $\&$ Sancar, 1987). Forms of photoreactivation have been reported which do not appear to involve DNA photo- lyase, but these tend to be inefficient and to occur only at short wavelengths (Jagger et al., 1970). Results of the present study therefore provide physiological evidence of the light-dependent enzymic repair of deleterious, UV-induced lesions of the $S$. acidocaldarius chromosome.

Unlike most other DNA-repair processes, which involve excision of damage and DNA resynthesis, photoreactivation results from direct reversal of the original structural damage. Its molecular mechanism has been studied in detail for several micro-organisms, and its basic features are believed to be widely conserved (Sancar \& Sancar, 1987). The primary deleterious effect of short-wave UV light is formation of cis-syn cyclobutane dimers between adjacent pyrmidine residues; the enzyme responsible for photoreactivation, DNA photolyase, cleaves the cyclobutane ring to yield the two original pyrimidine moieties (Sancar \& Sancar, 1988). The mechanism of cleavage appears to involve absorption of light by an enzyme-bound, accessory chromophore, followed by transfer of the excitation energy to an enzyme-bound $\mathrm{FADH}_{2}$, and transfer of an electron to the cyclobutane dimer. DNA photolyases bind specifically to DNA, including short oligonucleotides, containing pyrimidine dimers (Sancar \& Sancar, 1988).

The primary functional difference so far observed among DNA photolyases from various micro-organisms has been the nature of the accessory chromophore. Saccharomyces cerevisiae and Escherichia coli photolyases use a pterin derivative in this role (Sancar $\&$ Sancar, 1987) and their action spectra in vivo and in vitro have maxima near $380 \mathrm{~nm}$ (Sancar \& Sancar, 1988; Eker et al., 1991). Streptomyces griseus photolyase, in contrast, has an 8-hydroxy-5-deazaflavin derivative; the absorbance and action spectra of this photolyase each have a single maximum near $445 \mathrm{~nm}$ (Jagger et al., 1970; Sancar \& Sancar, 1988). Action spectra of photoreactivation of other micro-organisms generally conform either to the E. coli and S. cerevisiae type (e.g. Neurospora crassa) or to the Str. griseus type (Anacystis nidulans, Halobacterium cutirubrum and Methanobacterium thermoautotrophicum) (Jagger et al., 1970; Harm, 1980; Kiener et al., 1985; Eker et al., 1991).

Although resolution of its precise shape is limited by scatter in the values measured, the action spectrum of photoreactivation for UV-treated S. acidocaldarius cells appears significantly broader than either of the two classical types described above. It exhibits the longwavelength $(>420 \mathrm{~nm})$ activity characteristic of photoreactivation in archaea, $A$. nidulans and Str. griseus, but shows no decrease at shorter wavelengths. This contrasts sharply with the other archaea. At $367 \mathrm{~nm}$, for example, $M b$. thermoautotrophicum exhibited photoreactivation neither in vivo (Kiener et al., 1985) nor in vitro (Kiener et al., 1989), and Hb. cutirubrum exhibited only about $20 \%$ maximal photoreactivation (Eker et al., 1991); in contrast, S. acidocaldarius has its apparent maximum near that wavelength (Fig. 5). Another notable property of $S$. acidocaldarius photoreactivation 
observed in this study was only minor temperaturedependence of photoreactivation rate over the range of $50-24^{\circ} \mathrm{C}$ but an abrupt drop between 24 and $7{ }^{\circ} \mathrm{C}$. The former property is consistent with the predominantly photochemical nature of photoreactivation (Harm, 1980; Eker et al., 1991). It is interesting to speculate that the latter property may reflect a temperaturedependence of the photochemical rate constant, which for the Saccharomyces photolyase becomes apparent only below $0{ }^{\circ} \mathrm{C}$ (Harm, 1980). Resolving these and other mechanistic questions concerning the $S$. acidocaldarius photolyase will presumably require purification of the enzyme.

It is not clear from the present study whether $S$. acidocaldarius has mechanisms other than photoreactivation that can repair UV-induced damage to DNA. E. coli, for example, can excise short oligonucleotides containing pyrimidine dimers from DNA and resynthesize the affected strand. This is a function of the excision-repair system, which does not require visible light. One of the classical manifestations of excisionrepair of pyrimidine dimers, known as 'liquid holding recovery', is an increase in the viability of nongrowing cell suspensions incubated in the dark (Harm, 1980; Fitt et al., 1983; Eker et al., 1991). The halophilic archaeon Hb. cutirubrum lacks this response (Fitt et al., 1983). Analogous treatment of $S$. acidocaldarius cells (incubation at $75^{\circ} \mathrm{C}$ in dilution buffer) also failed to demonstrate liquid holding recovery (Fig. 2). However, it is perhaps premature to interpret this observation as evidence that Sulfolobus completely lacks excision or other dark repair of UV damage. Liquid holding at certain temperatures causes E. coli $\mathrm{C}$ and Schizosaccharomyces pombe to lose viability, for example, and this effect seems to reflect an activity of the excisionrepair enzymes (Harm \& Haefner, 1968).

The efficient photoreactivation of UV-killed S. acidocaldarius cells apparently represents the first DNA repair process of hyperthermophilic archaea to be measured in vivo. This phenomenon may provide new experimental approaches to the study of DNA repair processes at extremely high temperatures in archaeal cells. Among DNA repair processes, photoreactivation is unique in its specificity for DNA lesions formed only by UV radiation (Sancar \& Sancar, 1988). Efficient photoreactivation of $S$. acidocaldarius may therefore be taken as indirect evidence that $S$. acidocaldarius spp. routinely experience UV-induced damage in their natural habitats. Other forms of DNA damage in Sulfolobus species would seem inevitable, due to the known, deleterious effects of oxygen and high temperature on the covalent structure of DNA (Lindahl, 1993). It will be of future interest to investigate these forms of damage and their repair in Sulfolobus spp.

\section{ACKNOWLEDGEMENTS}

I thank K. Powell for technical assistance, E. Wood for conducting the preliminary experiments that first indicated photoreactivation of $S$. acidocaldarius, and K. Noll for critical reading of the manuscript. This work was supported by grant N00014-94-I-0393 from the US Office of Naval Research.

\section{REFERENCES}

Eker, A. P., Formenoy, L. \& DeWit, L. E. A. (1991). Photoreactivation in the extreme halophilic archaebacterium Halobacterium cutirubrum. Photochem Photobiol 53, 643-651.

Fitt, P. S., Sharma, N. \& Castellanos, G. (1983). A comparison of liquid-holding recovery and photoreactivation in halophilic and non-halophilic bacteria. Biochim Biophys Acta 739, 73-78.

Grogan, D. W. (1989). Phenotypic characterization of the archaebacterial genus Sulfolobus: comparison of five wild-type strains. J Bacteriol 171, 6710-6719.

Grogan, D. W. (1991). Selectable mutant phenotypes of the extremely thermophilic archaebacterium Sulfolobus acidocaldarius. J Bacteriol 173, 7725-7727.

Grogan, D. W. (1996). Exchange of genetic markers at extremely high temperatures in the archaeon Sulfolobus acidocaldarius. J Bacteriol 178, 3207-3211.

Grogan, D. W. \& Gunsalus, R. P. (1993). Sulfolobus acidocaldarius synthesizes UMP via a standard de novo pathway: results of a biochemical-genetic study. J Bacteriol 175, 1500-1507.

Harm, W. (1980). Biological Effects of Ultraviolet Radiation. Cambridge: Cambridge University Press.

Harm, W. \& Haefner, K. (1968). Decreased survival resulting from liquid-holding of UV-irradiated Escherichia coli C and Schizosaccharomyces pombe. Photochem Photobiol 8, 179-192.

Jagger, J., Takebe, H. \& Snow, J. (1970). Photoreactivation and killing in Streptomyces: action spectra and kinetic studies. Photochem Photobiol 12, 185-196.

Kiener, A., Gall, R., Rechsteiner, T. \& Leisinger, T. (1985). Photoreactivation in Methanobacterium thermoautotrophicum. Arch Microbiol 143, 147-150.

Kiener, A., Husain, I., Sancar, A. \& Walsh, C. (1989). Purification and properties of Methanobacterium thermoautotrophicum DNA photolyase. J Biol Chem 264, 13880-13887.

Lindahl, T. (1993). Instability and decay of the primary structure of DNA. Nature 362, 709-715.

McAfee, J. G., Edmondson, S., Datta, P., Shriver, J. \& Gupta, R. (1995). Gene cloning, expression, and characterization of the Sac 7 proteins from the hyperthermophile Sulfolobus acidocaldarius. Biochemistry 34, 10063-10077.

Sancar, G. B. \& Sancar, A. (1987). Structure and function of DNA photolyases. Trends Biochem Sci 12, 259-261.

Sancar, A. \& Sancar, G. B. (1988). DNA repair enzymes. Annu Rev Biochem 57, 29-67.

Stetter, K. O., Fiala, G., Huber, R. \& Segerer, A. (1990). Hyperthermophilic microorganisms. FEMS Microbiol Rev 75, 117-124.

Woese, C. R., Kandler, O. \& Wheelis, M. K. (1990). Towards a natural system of organisms: proposal for the domains Archaea, Bacteria, and Eucarya. Proc Natl Acad Sci USA 87, 4576-4579.

Received 5 August 1996; revised 6 November 1996; accepted 8 November 1996. 